\title{
A study of the impact of information disclosure quality on the efficiency of corporate investment-Based on civil engineering listed companies
}

\author{
Liying Zhang ${ }^{1, *}$ \\ ${ }^{1}$ Department of Accounting, Beijing jiaotong University, 100089 Beijing, China
}

\begin{abstract}
Most of the existing studies on the impact of disclosure quality of listed companies on the investment efficiency of enterprises are based on the static level, and the article investigates the evolution of disclosure quality on the investment efficiency of enterprises from the dynamic level by dividing the life cycle of enterprises. Taking the data of Shenzhen civil engineering companies from 2013-2017 as the research sample, it uses multiple regression analysis to empirically test the impact of disclosure quality of listed companies on the investment efficiency of enterprises at different life cycle stages. The results show that when no distinction is made between life cycle stages, high quality disclosure can significantly inhibit the inefficient investment behavior of firms; in the growth and maturity samples, high quality disclosure can significantly inhibit underinvestment and overinvestment; in the recessionary samples, high quality disclosure can significantly inhibit underinvestment and has no significant effect on overinvestment.
\end{abstract}

\section{INTRODUCTION}

The investment decision is the starting point and core content of the enterprise financial decision making, and the current research on the influencing factors of enterprise investment efficiency and other issues has been the hotspot of research of domestic and foreign scholars. In the process of enterprise development, the main factors affecting investment efficiency are the widespread problems of information asymmetry and agent conflict in the modern capital market. Information asymmetry will hinder enterprises in the financing process, resulting in underinvestment; agent conflict will make the investment decision in the hands of management, resulting in the phenomenon of overinvestment. Therefore, how to improve the efficiency of corporate investment has also become an urgent priority for enterprises at present. In the research field of the quality of corporate information disclosure, most domestic and foreign scholars are conducting research from a static perspective, and almost no research is conducted from the dynamic perspective of corporate life cycle. Therefore, this paper mainly investigates the role mechanism of information disclosure quality on corporate investment efficiency in different life cycle stages through the study of Shenzhen civil engineering companies, enriches the economic consequences of information disclosure quality, broadens the study of the dynamic influencing factors of corporate investment efficiency, and provides reference for the governance of non-efficient investment and investor decision-making.

\section{THEORETICAL ANALYSIS RESEARCH HYPOTHESIS}

\subsection{The relationship and assumptions of disclosure quality and investment efficiency}

Researchers at home and abroad have studied the quality of information disclosure more extensively, mainly from the factors influencing the quality of information disclosure and the economic consequences of the quality of information disclosure. Accounting information disclosure is an important way for enterprises to transmit basic information about the company's relevant financial situation and business performance to external investors and stakeholders, which is conducive to alleviating internal and external information asymmetry and reducing underinvestment, while also providing effective supervision of internal managers, reducing agency problems and preventing over-investment. Liu et al. [4] analyze the impact of accounting information quality on the investment efficiency of enterprises from the perspective of product market competition, and the results show that high-quality accounting information has a positive impact on the investment efficiency of enterprises. Dou et al. [3] analyze the effects of accounting information quality and audit supervision on the investment efficiency of firms, and the study shows that accounting information quality can significantly mitigate the inefficient investment behavior of firms and that high quality audit supervision can strengthen this

\footnotetext{
* Corresponding author: 1185069217@qq.com
} 
effect. Cornaggia[1] found that high quality accounting information can reduce the information asymmetry between companies and investors, and can also reduce the cost of external financing, thus improving investment efficiency. The quality of information disclosure, as a corporate governance mechanism, can not only enable adequate disclosure of accounting information in the market and inhibit underinvestment, but also act as a supervisory incentive for the management of the firm and inhibit over-investment by the management. Therefore, Hypothesis 1 is formulated.

H1: The quality of disclosure can discourage underinvestment and overinvestment by firms.

\subsection{The relationship and assumptions of disclosure quality and investment efficiency at different stages of the corporate life cycle}

Mueller[5], who first introduced the concept of the life cycle of a firm, argues that the development of a firm is similar to that of a natural organism in that it undergoes a dynamic development from birth, growth, maturity, and decay. Since the sample selected for this paper are all listed companies, which are considered to have passed the start-up phase, this paper will focus on the impact of disclosure quality on investment efficiency of listed companies in the growth, maturity, and decline phases.

Generally speaking, enterprises in the growth stage are smaller, occupy a smaller share of the market, have low market recognition, and there is serious information asymmetry between creditors and enterprises. At the same time, enterprises at this stage continue to develop and gradually increase their profitability, and they face more investment opportunities, and when faced with numerous investment opportunities, management may over-invest for private interests when making investment decisions. Improved disclosure quality can significantly alleviate firms' financing constraints, reduce agency costs, reduce underinvestment and discourage overinvestment by management. Therefore, hypothesis $2 \mathrm{a}$ is formulated.

H2a: In the growth phase, the quality of disclosure discourages firms from over-investing and mitigates under-investment.

Enterprises in the maturity stage, the scale of operation is further expanded, the company's sales revenue is increasing, and its own cash flow is also increasing. The agency problem gradually becomes serious, and since the enterprise holds more sufficient own cash flow, the management increases investment in making investment decisions for its own benefit, leading to over-investment and other inefficient investment behavior. However, there are still financing constraints for firms in this period, and improved disclosure quality can have a governance effect on underinvestment, while discouraging overinvestment. Therefore, hypothesis $2 b$ is proposed.

$\mathrm{H} 2 \mathrm{~b}$ : At maturity, the quality of disclosure inhibits firms from over-investing and mitigates underinvestment.
Enterprises in recession, due to their fixed production and business model, decreasing market share, and chaotic internal management system, lead to decreasing profitability and enterprises facing losses or even bankruptcy and liquidation, when the agency problem is more serious than in growth and maturity. Improved quality of disclosure not only makes management more cautious in making investments and discourages underinvestment behavior, but also inhibits overinvestment behavior. Since the recession period is mainly caused by the short-sightedness of management that can lead to underinvestment, and internal management confusion makes disclosure less effective, the improvement of disclosure quality mainly inhibits underinvestment and has a less significant effect on the governance of overinvestment behavior. Based on the above analysis, hypothesis $2 \mathrm{c}$ is proposed.

$\mathrm{H} 2 \mathrm{c}$ : During the recession, the quality of disclosure mainly inhibits firms from underinvesting.

\section{RESEARCH DESIGN}

\subsection{Data sources and sample selection}

In this paper, the data of Shenzhen Civil Engineering Company from 2013-2017 is used as the research sample, and 151 data samples were finally selected after processing the samples. The data are from Wind database and Shenzhen Stock Exchange website. The data processing of this paper was done by Stata15.0.

\subsection{Model design and selection of variables}

This paper focuses on the impact of disclosure quality on investment efficiency at different life cycle stages and the following model is developed to test the proposed hypothesis based on the previous research hypothesis.

$$
\begin{aligned}
& \text { Inv }=\alpha 0+\alpha 1 D Q+\alpha 2 R O A+\alpha 3 \text { Lev }+\alpha 4 S A R+\alpha 5 \\
& \text { Growth }+\alpha 6 \text { Size }+\alpha 7 \text { MAR }+\alpha 8 \text { Top }+\alpha 9 C F+\varepsilon \\
& \text { Underinv }=\alpha 0+\alpha 1 D Q+\alpha 2 R O A+\alpha 3 \text { Lev }+\alpha 4 S A R+\alpha 5 \\
& \text { Growth }+\alpha 6 \text { Size }+\alpha 7 \text { MAR }+\alpha 8 \quad \text { Top }+\alpha 9 \quad C F+\varepsilon \\
& \text { Overinv }=\alpha 0+\alpha 1 D Q+\alpha 2 R O A+\alpha 3 \text { Lev }+\alpha 4 S A R+\alpha 5 \\
& \text { Growth }+\alpha 6 \text { Size }+\alpha 7 \text { MAR }+\alpha 8 \text { Top }+\alpha 9 C F+\varepsilon
\end{aligned}
$$

Where Underinv denotes underinvestment and Overinv denotes overinvestment. For the measurement of investment efficiency, this paper will draw on Richardson's [6] research method to measure the investment efficiency of a firm. The specific model is as follows.

$$
\text { Invt }=\alpha 0+\alpha 1 \text { Growth } t-1+\alpha 2 \text { Levt }-1+\alpha 3 \text { Casht }-1+\alpha 4
$$$$
\text { Sizet }-1+\alpha 5 \text { Rett }-1+\alpha 6 \text { Invt }-1+\varepsilon
$$

For the measurement of information disclosure quality (DQ), as the assessment results of authoritative organizations are more fair and objective, this paper will use the assessment results of the Shenzhen Stock Exchange as the basis of measurement. For the 
measurement of enterprise life cycle, this paper will draw on Dickinson's[2] classification method to classify the enterprise life cycle, which is mainly divided into four different life cycle stages: introduction period, growth period, maturity period and decline period.

In addition to the quality of information disclosure of listed companies will have an impact on the investment efficiency of the company, other factors will also affect the investment efficiency of the company, therefore, in the selection of control variables, this paper refers to the relevant literature and selects the return on total assets (ROA), gearing ratio (Lev), asset turnover rate (SAR), growth (Growth), size (Size), management expense ratio (MAR), equity concentration (Top), and own cash flow (CF).

\section{EMPIRICAL ANALYSIS}

\subsection{Descriptive statistics}

In this paper, Stata 15.0 software was used to conduct descriptive statistics on the data of Shenzhen civil engineering companies from 2013-2017, which mainly includes the maximum value, minimum value, mean value and standard deviation, and the results are shown in Table 1. From the overall descriptive statistics of the sample, it can be seen that the mean value of the disclosure quality of the sample companies is 3.42 , indicating that the overall quality of disclosure of the sample companies is good. The mean value of investment efficiency is 0.63 , which is still some distance from the standard deviation, indicating that the overall investment efficiency of the sample listed companies is not high.

Table 1. Descriptive statistics.

\begin{tabular}{|c|c|c|c|c|}
\hline variable & $\begin{array}{c}\text { minimum } \\
\text { value }\end{array}$ & $\begin{array}{c}\text { maximum } \\
\text { value }\end{array}$ & $\begin{array}{c}\text { average } \\
\text { value }\end{array}$ & $\begin{array}{c}\text { standard } \\
\text { deviation }\end{array}$ \\
\hline Inv & 0.00 & 21.13 & 0.63 & 0.82 \\
\hline DQ & 1.00 & 4.00 & 3.42 & 0.60 \\
\hline ROA & -1.35 & 1.86 & 0.06 & 0.07 \\
\hline Lev & 0.01 & 11.51 & 0.41 & 0.31 \\
\hline SAR & 0.00 & 12.37 & 0.66 & 0.58 \\
\hline Growth & -0.95 & 85.00 & 0.21 & 1.23 \\
\hline Size & 16.11 & 29.21 & 22.74 & 1.15 \\
\hline MAR & 0.00 & 4.82 & 0.11 & 0.13 \\
\hline Top & 0.00 & 0.95 & 0.56 & 0.17 \\
\hline CF & -6.81 & 8.44 & 0.06 & 0.16 \\
\hline
\end{tabular}

\subsection{Multiple regression analysis}

The regression results of the quality of information disclosure of listed companies on the investment efficiency of enterprises are shown in Table 2. The regression results show that in the full sample, which does not distinguish the life cycle stage, the regression coefficient between the disclosure quality of listed companies and the investment efficiency of companies is -0.095 , which is significantly negatively correlated at the $1 \%$ level; in the underinvestment sample, the regression coefficient between the disclosure quality and underinvestment is - 0.134 , significantly negatively correlated at the $1 \%$ level; in the over-investment sample, the regression coefficient between disclosure quality and over-investment is -0.090 , significantly negatively correlated at the $5 \%$ level, and the above findings fully validate the $\mathrm{H} 1$ of this paper, that is, the disclosure quality of listed companies can significantly inhibit the inefficient investment behavior of firms, underinvestment and over-investment.

Table 2. Regression results for disclosure quality and investment efficiency.

\begin{tabular}{|c|c|c|c|}
\hline variable & $\begin{array}{c}\text { full } \\
\text { sample }\end{array}$ & $\begin{array}{c}\text { underinvestme } \\
\text { nt }\end{array}$ & $\begin{array}{c}\text { overinvestmen } \\
t\end{array}$ \\
\hline DQ & $-0.095^{* * *}$ & $-0.134 * * *$ & $-0.090 * *$ \\
\hline ROA & $0.623^{* * *}$ & $0.549 * * *$ & 0.301 \\
\hline Lev & $0.282 * * *$ & $0.326^{* * *}$ & 0.031 \\
\hline SAR & $-0.052 * * *$ & -0.031 & -0.053 \\
\hline Growth & $0.074 * * *$ & $0.044 * * *$ & $0.315^{* * *}$ \\
\hline Size & $-0.045^{* * *}$ & $-0.063 * * *$ & -0.013 \\
\hline MAR & 0.101 & -0.009 & 0.213 \\
\hline Top & 0.079 & 0.009 & 0.151 \\
\hline $\mathrm{CF}$ & $-0.147 * *$ & $-0.217 * * *$ & 0.023 \\
\hline Adj. $\mathrm{R}^{2}$ & 0.032 & 0.045 & 0.061 \\
\hline $\mathrm{F}$ & 22.347 & 19.323 & 17.832 \\
\hline
\end{tabular}

Table 3. Regression results for disclosure quality and investment efficiency at different life cycle stages.

\begin{tabular}{|c|c|c|c|}
\hline variable & $\begin{array}{c}\text { growing } \\
\text { period }\end{array}$ & $\begin{array}{c}\text { ripening } \\
\text { period }\end{array}$ & recession \\
\hline \multicolumn{4}{|c|}{ underinvestment } \\
\hline
\end{tabular}




\begin{tabular}{|c|c|c|c|}
\hline DQ & $-0.192 * * *$ & $-0.041 * *$ & $-0.100 * *$ \\
\hline ROA & 0.342 & -0.398 & 0.039 \\
\hline Lev & $0.556 * * *$ & -0.078 & -0.105 \\
\hline SAR & -0.053 & -0.001 & -0.014 \\
\hline Growth & 0.025 & $0.057 * * *$ & -0.063 \\
\hline Size & $-0.099 * * *$ & -0.008 & -0.035 \\
\hline MAR & -0.162 & -0.134 & 0.198 \\
\hline Top & -0.003 & -0.043 & 0.134 \\
\hline $\mathrm{CF}$ & $-0.768 * * *$ & -0.046 & 0.020 \\
\hline Adj. R2 & 0.063 & 0.091 & 0.032 \\
\hline $\mathrm{F}$ & 14.522 & 16.076 & 2.686 \\
\hline \multicolumn{4}{|c|}{ overinvestment } \\
\hline DQ & $-0.103^{* *}$ & $-0.152 *$ & -0.039 \\
\hline ROA & 0.276 & -0.157 & 0.723 \\
\hline Lev & 0.154 & -0.057 & -0.198 \\
\hline SAR & -0.017 & $-0.239 * * *$ & 0.081 \\
\hline Growth & $0.367 * * *$ & $0.607 * * *$ & $0.167 * * *$ \\
\hline Size & $-0.056^{* *}$ & 0.008 & 0.045 \\
\hline MAR & -0.369 & $-0.845^{*}$ & $0.623 * * *$ \\
\hline Top & 0.075 & -0.035 & $0.578^{*}$ \\
\hline $\mathrm{CF}$ & $-0.628 * *$ & 0.500 & 0.083 \\
\hline Adj. R2 & 0.033 & 0.157 & 0.068 \\
\hline $\mathrm{F}$ & 5.654 & 16.106 & 3.555 \\
\hline
\end{tabular}

Table 3 shows the regression results for different life cycle stages, and the results in the table show that the effect of disclosure quality of listed companies on the investment efficiency of firms is different in different life cycle stages. In the growth stage firms, disclosure quality can both significantly inhibit underinvestment and overinvestment, and the inhibiting effect on underinvestment is more significant. In the mature sample, disclosure quality is able to significantly inhibit both underinvestment and overinvestment, but has a more pronounced effect on underinvestment. In the recessionary sample, the regression coefficient of disclosure quality and underinvestment is -0.100 , which is significantly negatively correlated at the $5 \%$ statistical level, and the regression coefficient of disclosure quality and overinvestment is -0.039 , which is also negatively correlated but insignificant, and this finding validates $\mathrm{H} 2 \mathrm{c}$.

\section{CONCLUSIONS}

This paper studies the impact of information disclosure quality on investment efficiency at different life cycle stages of enterprises from the dynamic perspective of enterprise life cycle, based on the data of Shenzhen Civil Engineering Company from 2013-2017. The results show that high quality information disclosure can effectively curb the inefficient investment behavior of firms, and the impact varies in different lifecycle stages. In both growth and maturity samples, high quality disclosure can inhibit over-investment and alleviate under-investment, and has a more significant effect on the investment efficiency of growth samples; in decline samples, high quality disclosure can alleviate under-investment and has an insignificant effect on overinvestment. From the results of the whole sample, the quality of information disclosure can significantly improve investment efficiency, therefore, enterprises should disclose information in a timely manner, the regulatory authorities should also strengthen the supervision of the disclosure of information, and standardize the form of information disclosure; from the different life cycle stage samples, the quality of information disclosure has different effects on investment efficiency, enterprises should develop corresponding policies according to different development stages, in order to improve the enterprises' investment efficiency. The findings of this paper have implications for external investors as well as for internal corporate governance.

\section{References}

1. J. Cornaggia, Y. Mao, X. Tian, J financ econ, 115,1(2015)

2. V. Dickinson, The Accounting Review, 86, 6 (2011)

3. W. Dou, L.L. Ma, H. Gong, Nanjing Audit Science Academy Journal, 12 (2015)

4. X.H. Liu, L.H. Zhang, JCU financ econ, 9 (2016)

5. D.C. Mueller, S.L. Yun, IE, 20,3 (1972)

6. S. Richardson, Rev Account Stud, 11 (2006) 